\title{
Discussion to the paper by W. D. Riding and M. Ambiavagar
}

ROBERTSON. All speakers claim good results for IPPV, but as I do not feel that any case has been made out for bronchial lavage I would like to see them being objective about their results and the measures they are suggesting. They are doing so many other things to their patients at the same time. Normally about $100 \mathrm{ml}$ of mucus are secreted by the bronchial tree each day, and if dehydration is present, then this quantity will be diminished and the sputum will become more viscous. Since everyone is stressing the importance of adequate hydration, it might be that this alone is quite effective when given with antibiotics. Further, there should be a distinction between the removal of a solid plug which has been advocated for years and originally by Philip Hugh Jones, and merely squirting solutions down the bronchi which might or might not make the patient cough, and which the patients object to very strongly if they are awake. I do not think a case had been made out for continuing intravenous adrenalin, because of its dangers, but the experimental or scientific evidence on aminophylline is conflicting. Some years ago John Cotes found that there is either no change in $\mathrm{PaO}_{2}$ or else it was lowered after intravenous aminophylline; last year Daly and Howard from Sheffield found that some patients had an increase and others a decrease of $\mathrm{PaO}_{2}$, and I wondered whether Dr Rees's few patients provide a sufficient basis to prophesy whether the $\mathrm{PaO}_{2}$ would go up or down after aminophylline. Ogilvie of Newcastle found that some $70 \%$ of the deaths from asthma were shown to be due to infection, and his patients did far worse if they had bronchitis. This means there is a clear need to cope with the infective element, whether or not the physician thinks that it is present.

Broom. With respect, I feel the issue here is quite clear. In a review of ninety fatal cases of bronchial asthma between 1922 and 1951 (Earle, 1953), only six necropsies did not show 'the bronchial tree plugged with sticky mucus'. As Houston, de Navasquez \& Trounce (1953) pointed out in the same issue of Thorax 'There is no doubt that the majority of patients diagnosed clinically as being in status asthmaticus recover, and presumably in these patients there is only partial bronchial plugging with added bronchial spasm which in time becomes amenable to treatment'. Four subsequent accounts (of six patients) reporting similar deaths while on steroids, and my own similar experience with three fatal cases, prompted me to practise intermittent positivepressure respiration (with manual inflation of paralysed and lightly anaesthetized patients via a Boyle's machine) in two cases of intractable status asthmaticus (Broom, 1960). Both were shocked (BP $<100 \mathrm{mmHg})$ before IPPV. On several occasions during the subsequent successful management of these patients, it proved impossible to inflate the chest, and chest expansion was only possible after bronchial lavage.

\section{References}

ВRоOм, В. (1960) Intermittent positive pressure respiration and therapeutic bronchial lavage in intractable status asthmaticus. Lancet, i, 899.

EARLE, B.V. (1953) Fatal bronchial asthma. Thorax, 8, 195. Houston, J.C., DE Navasquez, S. \& Trounce, J.R. (1953)
A clinical and pathological study of fatal cases of status asthmaticus. Thorax, 8, 207.

Grant. Dr Riding and his colleagues have not provided any convincing evidence to support their use of bronchial lavage in the resuscitation of the moribund $\triangle$ asthmatic. All their patients received, in addition to bronchial lavage, large doses of corticosteroids and a period of intermittent positive-pressure ventilation (IPPV), and it is difficult to sustain their claim that these patients might not have made an equally good recovery if bronchial lavage had been omitted. I have myself performed bronchial lavage in four cases under general anaesthesia, and my anaesthetist and $I$ regard it as a dangerous procedure. Although bronchial plugs and $\vec{\omega}$ casts were obtained from the washings, these obviously $\vec{c}$ constituted a tiny proportion of the total number present in the smaller bronchi, and we considered that the periods of severe hypoxia, which invariably occurred during the process of lavage, involved a risk to the patient's life out of all proportion to the benefit derived $\rightarrow$ from the removal of casts from few small bronchi. $\frac{D}{9}$ I take the view that the purpose of IPPV in status asthmaticus was to ensure rest, adequate oxygenation and efficient removal of $\mathrm{CO}_{2}$, pending relaxation of $\mathscr{G}$ 'bronchospasm' in response to corticosteroids. I feel that bronchial lavage, by gravely disturbing the patient and causing severe hypoxia, has precisely the opposite effects, and predict that the present wave of enthusiasm for this procedure will soon lose its momentum. I believe that its place will be taken by new and more effective methods of humidification which, used in conjunction with IPPV, will eventually prove to be a safer and more effective method of softening and dislodging bronchial casts.

BROOM. In reply to Dr Robertson's healthy clinical scepticism about the indications for and benefits of bronchial lavage, may I ask just what else has one to consider after apnoea has arrived from intraluminal occlusion of airways? When the early stages of asthma are presenting purely as a mural obstruction of airways, few would disagree that adrenaline, steroids and antibiotics where necessary can, and usually will, arrest an attack.

Fig. A1 shows a blood clot which is a cast of the lower trachea and right and left main bronchi, resulting from haemorrhage after tracheostomy for acute ascending polyneuritis. For the second time that day, I found the $S$ patient black in the face. Attempted resuscitation via $N$ a bronchoscope by the surgeon was unsuccessful, and $N$ it was only after the energetic instillation of some $50 \mathrm{ml} \omega$ of tap water that the specimen was raised from the trachea on the end of a Tiemann's gum elastic biocudé catheter.

The basic problem in severe bronchial asthma was well defined by Dean Swift, when Anthony Henley's $T$ farmer, dying of an asthma, said, 'Well, if I can get this breath once out, it shall never get in again'.

When discussing IPPV it is to my mind a matter for conjecture why artificial ventilation was suggested in anaesthesia only in 1934 by Guedel and only came into general medicine in 1953 after the classic work of Lassen. 
It was in 1543 that Andreas Vesalius, in the sixth volume of De Humanis Corporis Fabrica, reported that the aeration of an animal's lungs with bellows could maintain life despite penetration of the thoracic wall. It was in 1661 that Marcello Malpighi first clearly demonstrated the functions of the lungs: if the collapsed lungs of animals, living up to the time of opening the thorax, are filled again with air introduced by a pipe placed in the trachea, the movement of the heart is restored-it was almost extinguished-by the blood breaking into the left ventricle owing to the pressure made by the air.

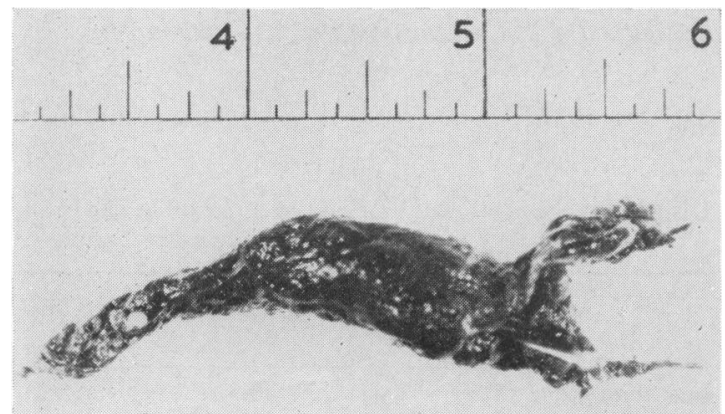

FIG. A1. A blood clot which is a cast of the lower trachea and right and left main bronchi, resulting from haemorrhage after tracheostomy for acute ascending polyneuritis.

Practice also helps us to prove this, for, when the vessels of the lungs are obstructed, inequality of the pulse appears at first and then finally death.

In 1665 an entry in Samuel Pepys' Diary reads as follows: 'I back presently to the Crowne Tavern behind the Exchange, by appointment, and there met the first meeting of Gresham College (The Royal Society) since the Plague. But what, amongst other fine discourse, pleased me most, was Sir G. Ent about respiration, that it is not to this day known, nor concluded on amongst physicians, nor to be done either, how the action is managed by Nature or for what use it is.'

The word Respire came into the English language in 1548 , yet there must be few of us today who would claim that all was known or concluded on amongst physicians about how the action is managed by Nature, or how it should be managed by them in unnatural circumstances. In the words of Vesalius 'I acknowledge no authority save the witness of my own eyes'. As I think we have seen this afternoon, there is a prima facie case for intermittent positive pressure ventilation and therapeutic bronchial lavage in otherwise intractable acute obstructive lung disease which is intraluminal in type (i.e. status asthmaticus of Grade V, M.R.C., 1956).

Ambiavagar. We too hope that mechanical means of treatment in asthma will be made unnecessary by the early institution of other measures, as stressed in our paper. However, the fact that D. A. Williams of Cardiff reports deaths from this disease despite a most enlightened regime of treatment, combined with our own experiences leads me to the inevitable conclusion that the method of treatment described by Riding will continue to have a place. In addition to bronchospasm, there is shedding of the mucosa and inspissation of bronchial secretions during asthma, combined with an ineffective cough. This is how plugs form in the bronchi, and plugs are always found at autopsy on asthmatics. We have found that bronchial lavage and endobronchial suction rapidly reduce airflow resistance and Thompson \& Pryor (1964) showed that bronchial casts were removed in sixty-seven lavages with consequent improvement of the clinical condition and respiratory function tests of their subjects. To aid the inexperienced, we have described in disproportionate detail how this procedure may be carried out safely and without hypoxia occurring. Further, most of our patients were unconscious, and when they were not, anaesthesia was used. They did not therefore, 'strongly object' to the procedure.

\section{Reference}

Thompson, H.T. \& Pryor, W.J. (1964) Bronchial lavage in the treatment of obstructive lung disease. Lancet, ii, 8.

\section{Editors' Note}

Since this symposium Thompson, Pryor and Hill have reported on the beneficial effects of bronchial lavage particularly in moribund asthmatics (Thorax, 1966, 21, 557). 